\title{
Evaluation of Nostril Symmetry Post-Cronin Labioplasty and Tajima Rhinoplasty in Unilateral Cleft Lip and Palate Cases
}

\author{
Teuku Nolly Iskandar ${ }^{1}$, Muhammad Syafrudin $\mathrm{Hak}^{2}$, Lilies Dwi Sulistyani ${ }^{3 *}$, \\ Pradono Suhardi ${ }^{3}$ \\ ${ }^{1}$ Oral and Maxillofacial Surgery Residency Program, Faculty of Dentistry, Universitas Indonesia, \\ Indonesia \\ ${ }^{2}$ Division of Oral and Maxillofacial Surgery, Cleft Lip and Palate Unit, Anak dan Bunda \\ Harapan Kita Hospital, Indonesia \\ ${ }^{3}$ Department of Oral and Maxillofacial Surgery, Faculty of Dentistry, Universitas Indonesia, \\ Jalan Salemba Raya no 4, Jakarta Pusat, DKI Jakarta 10430, Indonesia. \\ *Email: liliesdwi_s@yahoo.co.id
}

\begin{abstract}
Nasal deformity in cleft lip patients is caused by nasal septum deviation, alar cartilage distortion, and unparalleled maxillar and alveolar bones due to a widening of the palate. Additional rhinoplasty when using the labioplasty method is a solution to achieving nostril symmetry in unilateral cleft lip and palate (UCLP) patients. This study aims to compare nostril size and symmetry between the cleft and noncleft sides following Cronin method labioplasty in combination with Tajima method rhinoplasty. Methods: Nostril symmetry was evaluated according to the anthropometry scale based on profile photographs using nostril height, nostril width, and quarter-medial nostril height, and the nostril width in 35 UCLP patients following labioplasty in combination with Cronin and Tajima rhinoplasty methods. Results: The results showed significant differences $(\mathrm{p}<0.05)$ in width and quartermedial nostril height. In contrast, height and nostril width were not significantly different $p>0.05$. This shows that there is no significant difference in height and nostril width between the cleft and noncleft sides in patients post-Cronin method labioplasty and Tajima method rhinoplasty. In contrast, there is a significant difference in the width and quarter-medial nostril height. Conclusions: There is no significant difference in the height and nostril width post-Cronin method labioplasty and Tajima method rhinoplasty in UCLP patients. However, there is a significant difference in the width and quarter-medial nostril height between the cleft and noncleft sides.
\end{abstract}

Keywords: cronin method labioplasty, tajima method rhinoplasty, anthropometry, nostril symmetry

\section{Introduction}

Currently, primary and presurgical rhinoplasty is part of the management of patients with complete unilateral cleft lip and palate (UCLP). This technique has shown improved results in terms of nasal deformity and symmetry in general. Postlabioplasty results can be evaluated in terms of functional and aesthetic aspects. The 
functional aspect can be assessed by speech and vocalization. Esthetic aspects can be assessed by the appearance of the nose and lip [1].

The labioplasty technique used in the Rumah Sakit Anak dan Bunda (RSAB) Harapan Kita is the Cronin method, whereas the rhinoplasty technique used is the Tajima method. Labioplasty can improve the shape of the nose, which can be evaluated by using anthropometric techniques. Anthropometric analysis is a method that aims to achieve the most reliable comparison of the body shape by using specific landmarks determined by anatomical protrusions. From anthropometry, several landmarks can be determined that can be used as a reference for measurement. From these measurements, the symmetry of the nostrils can be assessed [2]. The purpose of this research is to determine and analyze the symmetry of the nostrils on the cleft and noncleft sides in UCLP patients post-labioplasty using the Cronin technique along with rhinoplasty using the Tajima technique.

The labioplasty technique conducted in the Unit Celah Bibir dan Palatum RSAB Harapan Kita was the Cronin technique, while the primary rhinoplasty technique used was the reverse- $\mathrm{U}$, also known as the Tajima technique. By using the Cronin technique, the orbicularis oris muscle can be returned to its proper place, thereby reducing the pressure on the tissue. The Cronin technique is a modification of the Tennison and Randall techniques, which raises the point of the incision $1 \mathrm{~mm}$ above the Cupid's bow. The Cronin technique has several advantages: it can be used for cases with very wide cleft lips; it can maintain the Cupid's bow; and it removes less tissue, leaves a smoother scar, and results in greater symmetry in the nostril floor and shape of the lips. The disadvantage is that there is some drooping of the lips on the cleft side [3].

Rhinoplasty with the reverse-U technique can change a nasal deformity into a normal or near-normal shape with surgical procedures and a minimal skin incision on the outer part of the nose [4]. With this technique, the cartilage can be opened and the chondromycocutaneous flap lifted from the cleft side of the nostril [1]. Then, the alar cartilage is sewn onto the contralateral side and the lateral cartilage from both sides so that the reverse-U flap is medially rotated [5]. Anthropometry can also be used to measure the height, quarter-medial height, and width of the nostril. Using the reverse-U technique, nasal cartilage is rotated medially and upward so that the quarter-medial height of the nostril is measured [6-8].

Photographs were taken of the inferior side. Measurements were taken by one person in triplicate. The average of the three measurements was used to compile real data.[9] From the photographic results, some landmarks were determined to be a basic measurement on the cleft and noncleft sides so that the size an symmetry between the nostrils of the cleft and noncleft sides could be compared.

\section{Methods}

This research was an observational, analytic study using anthropometric measurements conducted indirectly in UCLP patients post-labioplasty along with rhinoplasty between the ages of 4 and 6 years. Data were retrieved from patient records at Unit Celah Bibir dan Langit-Langit RSAB Harapan Kita from 2010 to 2012. Data were collected on patients who underwent labioplasty surgery at Unit Celah Bibir dan Langit-Langit RSAB Harapan Kita. Then, using medical record data, patients 
who fit the criteria were chosen and contacted by phone. Informed consent was obtained, and measurements of facial soft tissue (anthropometry) were taken indirectly from photographs.

\section{Results}

The number of subjects in this study totaled 35 , and the patient distribution by sex and UCLP side is shown in Table 1. The average nostril height on the noncleft side (normal) was $6.52 \pm 0.94 \mathrm{~mm}$, while on the cleft side, it was $6.05 \pm 1.13 \mathrm{~mm}$. The average nostril width on the noncleft side (normal) was $7.99 \pm 1.06 \mathrm{~mm}$, while on the cleft side it was $9.13 \pm 1.55 \mathrm{~mm}$. The average quarter-medial height of the nostril on the noncleft side (normal) was 5:30 $\pm 0.98 \mathrm{~mm}$, whereas on the cleft side it was $4: 29 \pm 1: 05 \mathrm{~mm}$. The average width of the nostril on the noncleft side (normal) was $41.66 \pm 8.72 \mathrm{~mm} 2$, whereas on the cleft side it was $45.98 \pm 11.85 \mathrm{~mm} 2$.

Table 1. Distribution based on gender and UCLP side

\begin{tabular}{|l|c|c|c|}
\hline \multirow{2}{*}{ Gender } & \multicolumn{2}{|c|}{ Diagnosis } & \multirow{2}{*}{ Total } \\
\cline { 2 - 3 } & Right UCLP & Left UCLP & \\
\hline Men & 10 & 15 & 25 \\
Women & 2 & 8 & 10 \\
Total & 12 & 23 & 35 \\
\hline
\end{tabular}

\section{Discussion}

Patients with nasal deformities are divided into three categories based on the size of the correction required in the alar cartilage. These categories are mild, moderate, and severe. In the mild category, elongation of the columella is unnecessary. In the severe category, the columella is elongated by more than $5 \mathrm{~mm}$. Intermediate cases are categorized as moderate. Mild cases only require an incision in the alar rim; a reverse-U incision also can be performed. For moderate cases, the alar cartilage can be repositioned, or a graft can be employed. Severe cases require a reverse-U incision or open rhinoplasty using a $\mathrm{V}-\mathrm{Y}$ incision on the columella. Concha cartilage grafts or composite grafts can be used to lengthen the columella [10].

Nostrils that were of the same height in the cleft and noncleft sides were due to upward pushing of the reverse-U flap and the medial wall of the nostril and the suturing of its lateral and contralateral cartilage. In addition, overcorrection on the cleft side is believed to compensate for the possibility of relapse during the healing period.

Differences in the width and quarter-medial height of the nostril were due to relapse during growth. The cause of the relapse is tension in the lateral wall of the nasal vestibule on a reverse $U$ flap rotation and difficulty encountered when suturing the innercartilage. Tension can be avoided by adequate release on the tissue. Another way to avoid tension is to perform stitch eversion. Relapses can also be due to the scar tissue [11].

A scar is a protrusion of the skin caused by an accumulation of fibrous tissue instead of normal collagen tissue. Scarring can be caused by several factors, some of which are described below. Thin, wrinkled, pale, and dry skin is likely to produce scarring. Unfavorable scars can be produced on the shoulder and sternum, whereas 
an incision in the eyelid area usually heals without scarring. Skin elasticity in children can also result in extensive scarring. In addition, the tension present after wound closure can cause scarring. The direction of the incision also can affect the formation of a scar. The incision should be made parallel to Langer's lines. The possibility of scarring increases when incisions cross Langer's lines because there will be a contraction in the area. Local conditions, such as injury or damage to the skin that adheres to the wound, also can result in scarring. Systemic conditions, such as vascular disease, and nutritional status, such as malnutrition and vitamin deficiency, can affect the likelihood of scarring. The surgical technique is also very influential: minimal damage to the skin edges, debridement of necrotic or foreign objects, and tension-free wound closure will minimize the occurrence of scarring. Scars will undergo regression after 6 months [11].

The width of the nostril between the cleft and noncleft sides was influenced by the design of the reverse- $U$ incision, and the addition of a small incision on the lateral edge to the anterior facilitated the rotation time of the flap and maximized the results. It also is influenced by the acceleration of nose growth (growth spurt). Rapid growth of the nose occurs between the ages of 1 and 4 years. After 4 years of age, the growth acceleration will slow down (late accelerated growth) until 11-12 years of age [2].

\section{Conclusions}

Based on indirect anthropometric measurements taken from photographs, this study revealed differences in symmetry in the height, quarter-medial height, and width of the nostril between the cleft and noncleft sides in UCLP patients post-labioplasty with the Cronin method along with the Tajima rhinoplasty technique. There was symmetry in the height and width of the nostril between the cleft and noncleft sides in the UCLP patients, which could have been caused by the overcorrection and incision design of the Tajima technique. There was no symmetry in the width and quarter-medial height of the nostril between the cleft and noncleft sides in UCLP patients post-labioplasty with the Cronin method in combination with the Tajima rhinoplasty technique. This was affected by the tension, scarring, and elasticity of the nasal cartilage.

\section{References}

1. Okawachi T, Nozoe E, Nishihara K, Nakamura N. 3-Dimensional analyses of outcomes following secondary treatment of unilateral cleft lip nose deformity. J Oral Maxillofac Surg 2011;69 Suppl 2:322-32.

2. Farkas LG, Katic MJ, Hreczko TA, Deutsch C, Munro IR. Anthropometric proportions in the upper lip-lower lip-chin area of the lower face in young white adults. Am J Orthod 1984;86 Suppl 1:52-60

3. Cronin TD. A modification of the tennison-type lip repair. Cleft Palate J 1966;3:37682.

4. Lo L. Primary correction of the unilateral cleft lip nasal deformity: achieving the excellence. Chang Gung Med J 2006;29:262-7. 
5. Matsumoto K, Nozoe E, Matsunaga K, Nishihara K. Postoperative lip and nose forms following primary bilateral cleft lip repair selecting one / two stage surgery in comparison to those of healthy children. Oral Sci Int 2013;10:77-86.

6. Somensi RS, Giancolli AP, Almeida FL De, Bento DF, Raposo-Do-Amaral CA, Buzzo $\mathrm{CL}$, et al. Assessment of nasal anthropometric parameters after primary cleft lip repair using the mohler technique. Rev Bras Cir Plast 2012;27 Suppl 1:14-21.

7. Zhu L, Meng T, Shi B, Deng D. Anthropometric study of the upper lip of 1500 healthy children in chengdu, western china. Br J Oral Maxillofac Surg 2008;46 Suppl 7:55460 .

8. Etöz A, Ercan İ. Anthropometric analysis of the nose. In: Preedy VR. Handbook of anthropometry. New York: Springer; 2012. p.919-26.

9. Han K, Kwon HJ, Choi TH, Kim JH, Son D. Comparison of anthropometry with photogrammetry based on a standardized clinical photographic technique using a cephalostat and chair. J Cranio-MaxilloFac Surg 2010;38 Suppl 2:96-107.

10. Jeong H-S, Lee H-K, Shin K-S. Correction of unilateral secondary cleft lip nose deformity by a modified tajima's method and several adjunctive procedures based on severity. Aesthet Plast Surg 2012;36:406-13.

11. Thorne CH. Grabb \& Smith's Plastic Surgery. 6th ed. Philadelphia: Lippincott Williams \& Wilkins; 2007. 